\title{
Anastomosing hemangioma mimicking renal cell carcinoma in a kidney transplant recipient: a case report
}

\author{
Chang Seong Kim
}

Division of Nephrology, Department of Internal Medicine, Chonnam National University Medical School, Gwangju, Korea

Background: An anastomosing hemangioma is a very rare and benign vascular neoplasm, which is associated with end-stage kidney disease. Although there have been reports of anastomosing hemangiomas incidentally detected in the kidney or adrenal gland, previous studies have not reported anastomosing hemangioma misdiagnosed as a renal cell carcinoma in a patient before kidney transplantation.

Methods: A 35-year-old woman with lupus nephritis was admitted to the emergency room for suspected uremic symptoms of nausea and general weakness. She had received hemodialysis due to end-stage kidney disease, and a living-donor kidney transplantation from her father was planned. Contrast-enhanced computed tomography and magnetic resonance imaging findings indicated a $1.7-\mathrm{cm}$ renal cell carcinoma in the right kidney during the pre-kidney transplantation work-up. However, after nephrectomy, irregularly shaped vascular spaces of various sizes were observed; these spaces showed an anastomosing pattern. The radiological imaging findings of the anastomosing hemangioma are similar to those of a renal cell carcinoma. Therefore, histologic confirmation is necessary to prevent delay in listing for kidney transplantation.

Results: After kidney transplantation, kidney function is well and no tumor recurrence has been detected. Long-term surveillance is needed to detect anastomosing hemangiomas after kidney transplantation.

Conclusions: Here, we report a case of anastomosing hemangioma confirmed by radical nephrectomy performed simultaneously with a living-donor kidney transplantation in a 35-year-old woman. The case findings indicate that prompt surgical resection of an enhancing renal mass is necessary for patients who are scheduled to undergo kidney transplantation and may reduce the waiting period for kidney transplantation.

Corresponding author: Chang Seong Kim

E-mail: laminion@hanmail.net

(C) The Korean Society for Transplantation

This is an Open Access article distributed under the terms of the Creative Commons Attribution Non-Commercial License (http://creativecommons.org/licenses/by-nc/4.0/) which permits unrestricted non-commercial use, distribution, and reproduction in any medium, provided the original work is properly cited. 